\title{
AS DUAS GRANDES CRISES DO CONSTITUCIONALISMO DIANTE DA GLOBALIZAÇÃO NO SÉCULO XXI ${ }^{1}$
}

\author{
THE TWO GREAT CRISES OF CONSTITUTIONALISM IN THE FACE OF GLOBALIZATION IN THE \\ 21ST CENTURY
}

Francisco Balaguer Callejón ${ }^{2}$

Resumo: Ainda que a progressiva incorporação do constitucionalismo ao plano internacional e global implique avanços civilizatórios parciais, o certo é que o século XXI está provocando uma transformação essencial nas condições históricas que haviam dado lugar a sua formação e desenvolvimento. A globalização gerou um contexto caracterizado pela aceleração e transformação permanente, tanto no âmbito econômico como no tecnológico. As mudanças produzidas nas quase duas décadas do século XXI, alteraram substancialmente o mundo que conhecíamos até o final do século XX. Surgiram novos agentes de poder global tanto públicos como privados que não se vinculam aos valores inspiradores do constitucionalismo. NO caso dos públicos, porque se tratam de Estados autoritários nos quais não existem estruturas democráticas ou estas são muito débeis. No dos privados, porque vinculam sua atividade à lógica exclusiva do benefício econômico, desvirtuando os valores democráticos que haviam regido o espaço público até recentemente. A crescente permeabilidade do Estado aos agentes globais que agem no plano financeiro e comunicativo, determinou as duas grandes crises do constitucionalismo frente à globalização neste século XXI. Por um lado, a crise financeira, que deu lugar a uma exteriorização do poder estatal, submetido plenamente às condições econômicas ditadas do exterior. Por força da crise tentou-se implantar uma "interpretação econômica da Constituição" que debilitou os valores inspiradores do constitucionalismo. Por outro lado, a crise democrática, manifestada a partir do Brexit e das eleições presidenciais norte-americanas, com a incidência que tiveram as grandes agências provedoras de serviços de Internet sobre os processos eleitorais, mediante o desenho tecnológico de pro- paganda massiva adaptada às redes sociais. O Estado-Nação encontra-se atualmente indefeso ante tais agentes globais da especulação financeira nos mercados e da manipulação publicitária do espaço público (que têm conexões entre si). O constitucionalismo de nossa época somente pode aspirar uma regulação global ou, senão, supranacional, eficaz. Para além dos efeitos visíveis da intervenção destes novos poderes globais, surgem alguns problemas estruturais que podem afetar a própria essência do constitucionalismo em sua última fase de desenvolvimento até o momento, aquela representada pelas constituições normativas e a democracia pluralista. No plano econômico, minam-se as bases o Estado social e deterioram-se suas raízes culturais. No plano comunicativo, apesar da potencialidade participativa que têm as redes sociais, percebe-se um isolamento e encapsulamento da coletividade em grupos e uma mudança de padrões de conduta nos partidos políticos e nos meios de comunicação, que dificultam cada vez mais os processos comunicativos reflexivos, orientados no sentido da formação de consenso, que eram próprios da democracia pluralista. A segmentação e desagregação progressivas do espaço público se veem potencializadas extraordinariamente pelas redes sociais, já que lhes resulta economicamente produtiva às grandes plataformas de Internet. $\bigcirc$ fomento da instabilidade política e de conflitos sociais virtuais através das redes incrementa sua receita publicitária. A lógica economicista instalada nos grandes agentes globais está provocando um retrocesso civilizatório e uma crise existencial para o constitucionalismo como nós o conhecemos.

Palavras-chave: Constitucionalismo. Redes sociais. Crise financeira. Globalização.

\footnotetext{
Traduzido do espanhol por Hugo César Araújo de Gusmão.

2 Catedrático de Derecho Constitucional de la Universidad de Granada, Espanha; Catedrático Jean Monnet de Derecho Constitucional Europeo; Catedrático Jean Monnet ad personam de Derecho Constitucional Europeo y Globalización Publicaciones; Avda. del Hospicio, C.P. 18010, Granada, España; balaguer@ugr.es; https://orcid.org/0000-0001-8084-7890
} 
Abstract: Even if the gradual incorporation of constitutionalism on the international and global level involves partial civilizing advances, the truth is that the 21 st century is causing an essential transformation in the historical conditions that led to its formation and development. Globalization has generated a context characterized by acceleration and permanent transformation, both in the economic and technological fields. The changes that have taken place in the almost two decades of the 21 st century have substantially altered the world that we had known until the end of the 20th century. New agents of global power, both public and private, which are not linked to the values that inspired constitutionalism, have emerged. In the case of the public powers, because they are authoritarian states which lack of democratic structures. In the private sector because they have linked their activity to the exclusive logic of economic benefit, distorting the democratic values that had ruled until recently the public sphere. The increasing permeability of the State to the global agents that act in the financial and communicative plane, has determined the two great crises of the constitutionalism in front of the globalization in this 21st century. On the one hand, the financial crisis, which has led to an outsourcing of a state power fully subject to economic conditions that have been dictated from outside. On the occasion of the crisis, an attempt has been made to implement an "economic interpretation of the Constitution" that has weakened the inspiring values of constitutionalism. On the other hand, the democratic crisis, which has manifested itself from the Brexit and the US presidential elections, with the impact that the large Internet service provider agencies have had on the electoral processes, through the technological design of adapted mass propaganda to social networks. The Nation State is currently defenceless against these global agents (which have connections among themselves) of financial speculation in the markets and public space manipulation. The constitutionalism of our time can only aspire to a global or, at least, supranational regulation, to be effective. Beyond the visible effects of the intervention of these new global powers, some structural problems are being generated that may affect the very essence of constitutionalism in its last phase of development until now, that represented by normative constitutions and pluralist democracy. At the economic level, the foundations of the social and democratic State of Law are being undermined and their cultural roots are deteriorating. On the communicative level, despite the participative potential of social networks, there is a growing isolation and encapsulation of citizenship in groups and a change in behaviour patterns in political parties and in the media, which make more and more difficult reflective communicative processes, oriented to the formation of consensus, which were typical of pluralist democracy. Social networks are extraordinarily enhancing the segmentation and progressive disintegration of the public space, since it is economically productive to the large Internet platforms. The generation of political instability and virtual social conflicts through networks increases their advertising revenues. The economist logic that has been installed in the great global agents is provoking a civilizing setback and an existential crisis of the constitutionalism that we have known up to now.

Keywords: Constitutionalism. Social networks. Financial crisis. Globalization.

Data de submissão: 16 de fevereiro de 2019 Avaliado em: 16 de fevereiro de 2019 (AVALIADOR A) Avaliado em: 16 de fevereiro de 2019 (AVALIADOR B) Aceito em: 17 de fevereiro de 2019

\section{Introdução}

A crescente permeabilidade do Estado aos agentes globais que atuam no plano financeiro e comunicativo, determinou as duas grandes crises do constitucionalismo frente a globalização neste século XXI. Poderíamos afirmar que ambas são crises democráticas no que tange ao seu resultado final, porque ambas dão lugar a processos de involução democrática. Porém, enquanto uma delas gerou uma involução democrática "externa" no sentido de que se produz externamente em relação 
aos processos políticos estatais, mediante a imposição de condições econômicas limitadoras da capacidade de ação do Estado, a outra gerou uma involução democrática "interna" porque afeta o próprio núcleo dos processos políticos estatais, mediante a interferência em processos eleitorais e no debate público em geral de grandes plataformas que gerenciam redes sociais e que almejam determinar os resultados destes processos por meio da manipulação propagandística massiva.

Por um lado, cronologicamente, a primeira foi a crise financeira, que deu lugar a uma exteriorização do poder estatal, submetido a condições econômicas ditadas de fora. Sob o pretexto da crise, tentou-se implantar uma "interpretação econômica da Constituição" (BALAGUER, 2012a) que debilitou os valores inspiradores do constitucionalismo, afetando em grande medida a legitimidade das constituições nacionais. A economia tentou usurpar o espaço não só da política, como também o da própria Constituição, marginalizando-a e convertendo-lhe numa instituição residual no espaço público, perdendo em grande medida sua força normativa, seu caráter pluralista e sua condição de fator regulador da dinâmica social (BALAGUER, 2013c).

Por outro lado, a crise mais recente foi a de caráter democrático, interna, e gerada pelas redes sociais, que se manifestou a partir do referendo sobre o Brexit e das últimas eleições presidências dos Estados Unidos, com a incidência que tiveram as grandes agências provedoras se serviços de internet sobre os processos eleitorais, mediante o desenho tecnológico de propaganda massiva adaptada às redes sociais. A involução democrática gerada por ocasião da crise financeira é muito grave porque altera as condições estruturais básicas do constitucionalismo europeu (direitos fundamentais, direitos sociais, descentralização política, normatividade da Constituição, divisão de poderes na relação entre Executivo e Legislativo). Porém, a involução democrática interna é ainda mais grave por afetar os processos políticos de formação da vontade estatal internalizando o poder dos grandes agentes globais.

Deste ponto de vista, ambas as crises geraram, de maneira complementar, uma debilidade cada vez maior na democracia pluralista. Por um lado, a financeira reduz o pluralismo ao obrigar o Estado, qualquer que seja a orientação política de seus governantes - isto é, seja o que for que pensem em relação a forma de se produzir a ação estatal - a realizar as políticas impostas do exterior (em última instância condicionadas pelos especuladores financeiros). Por seu turno, a crise comunicativa é ainda mais problemática, por que não se limita a condicionar o Estado de fora, pretendendo, ao contrário, subverter os processos democráticos de formação da vontade estatal para determinar de dentro de tais processos a vontade dos governantes. Não se trata de dizer aos representantes democráticos o que devem fazer em virtude das exigências econômicas externas, embora pensem de maneira diferente, e sim de definir diretamente o que devem pensar para poder converter-se em opções de governo, através da manipulação propagandística de seus votantes.

Lamentavelmente, com isto não acabam os problemas gerados pelas duas grandes crises do capitalismo de nosso tempo. Para além dos efeitos visíveis da intervenção destes novos poderes globais, estão surgindo problemas estruturais que podem afetar a própria essência do constitucionalismo 
em sua última fase de desenvolvimento até o momento, aquela representada pelas constituições normativas e pela democracia pluralista. No plano econômico, estão sendo minadas as bases do Estado social e deterioradas suas raízes culturais. No plano comunicativo, apesar da potencialidade participativa das redes sociais, está se produzindo um crescente isolamento e encapsulamento da coletividade em grupos e uma mudança de padrões de conduta nos partidos políticos e nos meios de comunicação, que dificultam cada vez mais os processos comunicativos reflexivos, orientados à formação de consensos, que eram típicos da democracia pluralista.

A segmentação e desagregação progressiva do espaço público se veem potencializadas extraordinariamente pelas redes sociais, já que se apresentam como economicamente produtivas para as grandes plataformas eletrônicas. $\bigcirc$ advento da instabilidade política e dos conflitos sociais virtuais através das redes incrementa os recursos publicitários percebidos. A lógica economicista instalada nos grandes agentes globais está provocando um retrocesso civilizatório e uma crise existencial do constitucionalismo como o conhecemos.

Estamos assistindo uma transformação dos padrões culturais que haviam regido a vida pública das sociedades democrática no constitucionalismo moderno, e também uma mudança de paradigma. Esta mudança de paradigma não pode ser divisada com precisão ainda devido às dinâmicas tão aceleradas geradas nesta temática, que periodicamente fazem com que surja alguma novidade em relação às linhas significativas de transformação na utilização das redes sociais com finalidades diversas embora geralmente vinculadas ao benefício econômico das plataformas ou os agentes globais que as utilizam. Este ritmo dificulta muito a análise científica, porquanto tornase impossível conhecer previamente os efeitos que tais transformações terão em médio e longo prazo. A reflexão teórica tem que extrair destas incipientes linhas as tendências que possivelmente incidirão no espaço público, na configuração democrática dos países analisados e em seus processos constitucionais.

Como tentaremos argumentar neste trabalho, a ação combinada de uma pressão econômica de base derivada da globalização, evidenciada de maneira inequívoca com a crise financeira desde 2008, d de uma crescente intervenção das plataformas que gerenciam redes sociais nos processos políticos (evidente especialmente a partir de 2016, quando teve seu "ensaio geral no referendo sobre o Brexit) está provocando uma transformação das condições materiais e das pauta culturais do constitucionalismo e dando lugar a uma mudança de paradigma. Caso esta mudança se consolide, estaríamos ante um constitucionalismo isolado, residual, que não poderia cumprir as funções históricas que lhe caracterizam. Um constitucionalismo sem legitimidade diante das demandas históricas e tecnológicas de nosso tempo, tendente a permanecer marginalizado em relação aos processos políticos reais, e que seria incapaz de controlar os autênticos poderes de nossa época e de garantir os direitos fundamentais diante destes poderes.

Isto acontece justamente quando o constitucionalismo havia logrado controlar o essencial no poder do Estado através de mecanismos políticos e jurídicos de cobrança de responsabilidade 
estabelecidos nas constituições normativas. O motivo fundamental consiste no fato deste poder, antes exercido no seio do Estado nacional, ter se desvinculado cada vez mais do Estado, sendo exercido agora por instâncias globais. Portanto, o constitucionalismo tem que esboçar novas estratégias que possibilitem a recuperação das funções históricas que the caracterizaram como movimento civilizatório, para controlar o poder aonde este se encontra atualmente, em grande medida fora do Estado e dos circuitos internos de formação da vontade estatal.

\section{A "era dourada" do constitucionalismo no seio do Estado nacional e seu declínio}

C constitucionalismo das constituições normativas representeou a grande construção teórica que possibilitou o controle do poder do Estado, a garantia dos direitos fundamentais e a articulação democrática e pacífica dos conflitos sociais e políticos na Europa após a Segunda Guerra Mundial. Porém, esta construção se desenvolve num momento histórico em que o processo de globalização começa a se ativar de novo e o processo de integração supranacional na Europa dá seus primeiros passos. Em ambos os casos, o constitucionalismo encontra-se ausente inicialmente e não começará a se projetar, especialmente no que tange à integração europeia, até muito recentemente. Em certo sentido poderíamos afirmar que a época de plenitude do constitucionalismo levará consigo o germe de sua posterior decadência, precisamente porque tenta regular o poder, então concentrado no Estado, e este poder começa a se desvincular progressivamente do Estado na mesma época em que são aprovadas na Europa as primeiras constituições normativas: a alemã e a italiana, que agora completa 70 anos.

Porém, não será até o século XXI, com o ritmo acelerado que a globalização está imprimindo ao tempo histórico atual, quando se evidenciará a incidência negativa que este processo pode chegar a manifestar sobre as condições materiais que possibilitaram o constitucionalismo das constituições normativas. Na verdade, se levamos em consideração os fatores que se encontram na base dos fenômenos de fragmentação social, polarização política, sectarismo, manipulação propagandística, desenvolvimento do populismo e, em última análise, involução democrática, podemos ver como o patrimônio constitucional europeu nos permite abordar estas questões com uma perspectiva histórica que nos habilitar aprender de experiências passadas. Estes fenômenos já estavam presentes no debate público anterior à consolidação das constituições normativas na Europa depois da Segunda Guerra Mundial, e que deram lugar àquilo que poderíamos denominar da "era dourada" do constitucionalismo (BALAGUER, 2012). Porém, neste momento, ainda era possível tentar resolver estes problemas no seio do Estado e por meio da Constituição, porque a economia e a política dependiam, em grande medida, da mediação estatal.

No entanto, o contexto da globalização deslocou grande parte do poder real dos Estados, situando-o nos circuitos financeiros, em sua vertente econômica, e nos agentes da comunicação global, em sua vertente política. Trata-se de uma mudança de paradigma, que debilita 
extraordinariamente o Estado e lhe deixa em grande medida inerte, dando lugar às duas grandes crises que o constitucionalismo teve que afrontar neste século XXI. Para compreender o alcance destas crises cabe considerar que o constitucionalismo surgiu historicamente como um movimento de controle do poder, concentrando-se essencialmente no poder do Estado. $\bigcirc$ aperfeiçoamento de técnicas e instrumentos de limitação do poder culmina com as constituições normativas no seio do Estado nacional, através de instâncias políticas e jurídicas que submetem as instituições a regras destinadas a garantir os direitos da coletividade e proteger os das minorias. Assim foi durante a segunda metade do século XX para muitos países europeus (Alemanha, Itália, França, Espanha, Portugal...). Porém, a partir do século XXI, o ritmo acelerado da globalização está situando fora do Estado âmbitos de poder cada vez mais amplos e intensos, que não estão submetidos a controle algum. Em grande medida, esta ausência de controle deriva dos avanços tecnológicos, que geram novas formas de lesão a direitos fundamentais impossíveis de prever, porque surgem da imposição dos interesses comerciais das grandes plataformas de internet, que se movimentam numa zona obscura para o Direito e, especificamente, para o Direito Constitucional.

Produz-se assim o paradoxo de que quando o constitucionalismo começa a culminar sua grande obra civilizatória na história da humanidade, começa também seu declínio, unido ao do próprio Estado como espaço de articulação do poder exercido sobre a coletividade. Nas duas grandes crises que ora analisamos, a primeira delas, a financeira, fez com que algumas constituições permanecessem em stand by (BALAGUER, 2012a), dando lugar a uma interpretação econômica da Constituição, que rompe com os princípios e valores estabelecidos nas constituições normativas.

A segunda crise deriva da capacidade de manipulação propagandística mediante a utilização de plataformas de comunicação, que alteraram as condições do espaço público e que intervieram de maneira muito eficaz em processos eleitorais tais como o Brexit ou as eleições presidenciais dos Estados Unidos. Plataformas que gerenciam redes sociais ou empresas que as utilizam, influíram na orientação do voto através de um tipo de propaganda que se parece muito com a propaganda subliminar e mediante a acumulação massiva de dados pessoais para a construção de perfis de usuário.

Os poderes que estão por trás destas crises situam-se à margem do Estado e da Constituição nacional. Cabem sérias dúvidas de que os Estados europeus tenham a capacidade para impor-lhes condições e garantir os direitos de sua coletividade em plenitude frente a tais poderes. A questão que se coloca então é se é possível recuperar o constitucionalismo estatal através do constitucionalismo supranacional.

\section{As insuficiências da integração supranacional europeia}

Frente à segunda globalização, que em sentido moderno se desenvolveu depois da Segunda Guerra Mundial, o processo de integração europeia resultou plenamente funcional para 
os Estados membros. A criação de um amplo mercado que superava as limitações dos mercados nacionais favoreceu o desenvolvimento econômico e possibilitou a limitação do poder de grandes multinacionais ante as quais os Estados nacionais mal tinham capacidade de manobra. Numa fase na qual a economia produtiva ainda predominava sobre a economia financeira e especulativa, o processo de integração permitiu afrontar a globalização e proteger os espaços nacionais dos Estados membros no que tangia a sua margem de decisão política e ao desenvolvimento da democracia pluralista. Tudo isso apesar de que a integração supranacional tenha se construído de costas para o Direito Constitucional e com um modelo no qual os interesses nacionais ocupavam (e continuam ocupando) a maior parte do debate público na Europa.

Assim, pois, frente a este processo, que limitava a capacidade dos Estados de atuarem num âmbito global e de decidirem sobre suas políticas internas, a integração supranacional possibilitou aos Estados europeus a recuperação de uma parte do poder perdido (BALAGUER 2011). Sendo a soberania estatal impossível em tempos de globalização, por meios da integração supranacional construiu-se um poder político compartilhado entre os sócios europeus através das instituições supranacionais. Durante a segunda metade do século XX, o modelo funcionou com estes elementos indentitários. Porém, no século XXI já nos encontramos antes magnitudes distintas, como ficou ressaltado com a última crise econômica, na qual as instituições europeias mostraram-se bastante ineficazes na proteção do euro e das economias de alguns Estados membros, colocando em grave risco o próprio projeto de integração, ao menos até a chegada de Mario Draghi à Presidência do Banco Central europeu em 2011.

Especialmente durante a crise econômica pudemos ver como alguns sistemas constitucionais, entre os quais se encontram o italiano e o espanhol, experimentaram uma involução extraordinária, devido à pressão dos mercados e à incapacidade do modelo atual de integração supranacional europeia para proteger os Estados membros da Eurozona frente aos especuladores financeiros (BALAGUER, 2013a). Esta involução tem uma origem externa que se relaciona com a mudança das condições históricas nas quais se desenvolve o constitucionalismo e que procede, em última instância, da aceleração do processo de globalização derivada do desenvolvimento tecnológico e científico. Naturalmente, esta involução gerou mal-estar em amplos setores da sociedade, retirando a legitimidade tanto do projeto europeu como dos próprios sistemas constitucionais internos, como consequência do aumento da desigualdade, das reduções de direitos sociais e da degradação das condições de vida.

Na verdade, o atual modelo de integração europeia é tudo menos excessivamente europeísta. Ao potencializar os interesses dos Estados, contribui para reforçar a identidade nacional, fazendo com que a Europa perceba a si mesma como uma oportunidade de melhorar as próprias posições ou como uma ameaça frente aos distintos setores sociais, aos quais se transfere habitualmente a ideia de que a responsabilidade pelas políticas que lhe prejudica é europeia e não dos governos dos Estados membros. Durante muitos anos, com este modelo de integração, a Europa foi - nos termos 
do vocabulário economicista estendido a partir da crise - o banco ruim ao qual foram transferidos "ativos tóxicos" das políticas econômicas esboçadas para afrontar, com maior ou menor sorte, o processo de globalização. Um modelo assim não pode mais que fragilizar a identidade europeia, que dificilmente poderá construir-se caso o modelo de integração supranacional atual continue se mantendo (BALAGUER, 2013b).

Por outro lado, o modelo de integração não seguiu o caminho, natural e coerente com o patrimônio constitucional europeu, de construção constitucional da Europa, mas desabilitou em grande medida as funções próprias do Direito Constitucional, em particular o controle do poder e a canalização dos conflitos sociais e políticos por meio da democracia pluralista (DE CABO, 2009) embora também a garantia dos direitos, tanto nos períodos iniciais da construção europeia como paradoxalmente - nos últimos anos, como consequência das políticas implementadas para afrontar a crise econômica. Desafortunadamente, este impacto sobre as funções do Direito Constitucional não é apreciável somente no nível europeu, mas reflete-se também no âmbito interno, de maneira que se perdeu densidade democrática nos Estados membros devido ao modelo de integração que seguimos até o momento.

\section{A exteriorização do poder estatal por meio da economia}

Apesar de tudo, a integração europeia representou uma história de êxito durante o período em que transcorreu dentro do século XX, acomodando-se em grande medida a seu tempo histórico e às condições econômicas em que se desenvolvia dentro do processo de globalização, como evidenciam as sucessivas ampliações e o fato de que houvesse candidaturas permanentes para incorporação ao projeto europeu. É difícil destacar uma data na qual se possa dizer que esta situação se transformou, ao ponto de dar lugar à primeira saída voluntária da União Europeia, o Brexit, assim como a dificuldades internas e conflitos muito agudos, impensáveis nos primeiros quarenta anos do processo de integração. Na verdade, as condições externas da globalização começaram a mudar, talvez de forma pouco perceptível, já com a primeira crise do petróleo nos anos 70 e o desenvolvimento progressivo de grandes bolsas de capital financeira e especulativo. A queda do muro, a integração dos países do Leste Europeu, a unificação alemã e a adoção e implementação do Euro, são outros dos fatores que mudariam a ordem global mantida estável durante mais de quarenta anos depois da Segunda Guerra Mundial.

A crise da Eurozona evidenciou a inadequação de uma modelo de integração pela metade, que carecia das condições para um autêntico governo econômico da Europa e que deixou alguns Estados membros indefesos ante os especuladores financeiros, aos quais não podiam fazer frente devido às condições da integração na zona Euro e à impossibilidade de afrontar cum uma divisa própria a crise, conforme haviam feito em crises anteriores. Ademais, os ataques ao Euro deixaram clara a impossibilidade de contar com a proteção dos Estados Unidos no processo de integração, como 
havia ocorrido historicamente quando a moeda alemã servia como competidora do dólar (ARJONA, 2017). O aumento constante da posição do Euro como moeda de reserva nos anos anteriores à crise gerou uma inevitável rivalidade com o dólar, que já não se adequava às condições nas quais havia se desenvolvido a integração europeia durante o século XX. Porém, seria necessário esperar pela Administração Trump para que os principais líderes europeus assumissem esta nova realidade geopolítica e a necessidade de voltar a abordar as bases do projeto europeu, mantidas relativamente inalteradas desde sua gênese, num mundo muito diferente do atual.

Os desafios enfrentados hodiernamente pelo projeto europeu são enormes e os meios com os quais conta são muito limitados caso se mantenha o modelo atual de integração supranacional. Não se trata unicamente do declínio das antigas potências europeias frente aos países emergentes ou da própria União Europeia frente a China no que concerne a sua posição na distribuição do PIB mundial. O problema é que enquanto não houver uma unidade de decisão no âmbito europeu, democraticamente respaldada pela comunidade, enfrentamos os agentes mundiais que, ou têm recursos naturais que lhes permitem nutrir suas estruturas produtivas, ou estão se posicionando na luta por tais recursos, adquirindo posições de vantagem que dificilmente poderão ser revertidas no futuro em favor da União Europeia. A ausência de uma política energética europeia, de uma política de defesa europeia e de muitas outras que requerem uma atuação unitária em nível europeu, para fazer frente às condições atuais da globalização, só pode nos deparar com um declínio maior das economias dos Estados membros no futuro.

Naturalmente, esta situação só poderia se ver mitigada ou ser resolvida mediante uma integração europeia intensificada. O problema, no entanto, é que a escassa legitimação do projeto europeu se estendeu progressivamente com as políticas impulsionadas pelas instituições europeias para fazer frente à crise econômica, dando lugar a fenômenos como o Brexit, e a que amplos setores da população em países anteriormente muito europeístas se declarem agora já não eurocéticos, mas abertamente antieuropeus.

Não se pode ignorar que as políticas europeias de austeridade desenvolvidas por força da crise econômica alteraram os grandes consensos constitucionais de alguns dos Estados membros. Em particular, a democracia pluralista viu-se submetida a uma forte tensão derivada da aplicação incondicionada das políticas de austeridade europeias, tensão esta que impediu qualquer proposta política que não fosse coerente com tais políticas, determinando a inviabilidade dos programas eleitorais apresentados pelos partidos e referendados pela coletividade mediante a conformação de maiorias governamentais. O círculo de decisão previamente delimitado a partir de instâncias globais e supranacionais não deu espaço para o pluralismo político, exteriorizando assim o poder estatal, e submetendo-lhe a condições econômicas ditadas em grande medida pelos especuladores financeiros e os grandes fundos de investimento globais.

mesmo pode ser dito das políticas sociais e dos direitos sociais, que foram um elemento fundamental no pacto social que deu lugar às constituições normativas na Europa. $\bigcirc$ declínio dos 
direitos sociais e trabalhistas foi de tal envergadura que as próprias instâncias europeias, conscientes da escassa legitimação gerada em amplos setores da população europeia, puseram em marcha recentemente o chamado "pilar social europeu", com a intenção de recuperar de alguma forma a capacidade de integração social do projeto europeu mediante o esboço de novas políticas com um conteúdo especificamente social e trabalhista e a recuperação do diálogo social, interrompido durante a crise. Não se pode ignorar, no entanto, que muito além do positivo que é o fato da União Europeia prestar atenção específica a esta dimensão social, as regras do jogo estabelecidas para afrontar a crise econômica continuam vigentes e, como se reconhece pelas próprias instituições europeias, representam um elemento condicionante necessário das novas políticas sociais (BALAGUER, no prelo).

Em última instância a normatividade da Constituição também se ressentiu, precisamente porque os grandes consensos constitucionais do período constituinte estavam garantidos pela própria Constituição que, no entanto, demonstrou-se ineficaz para fazer valer os princípios e preceitos constitucionais frente a pressão orçamentária imposta a partir de instâncias globais e supranacionais (BALAGUER, 2018b). Até certo ponto a democracia e a Constituição na Europa converteram-se, durante o período da crise, num luxo al alcance apenas daqueles Estados membros que tinha uma melhor posição econômica e que, portanto, não viram condicionados seus grandes pactos constitucionais por força das políticas implementadas com a crise econômica. Em última análise, frente à "Constituição econômica" do Estado social, que equilibrava os fatores produtivos propiciando políticas sociais que tinham uma vocação emancipatória, produziu-se uma hipertrofia da economia que, sem modificar o texto, gerou uma interpretação econômica da Constituição que acabou alterando os fundamentos do nosso sistema constitucional (BALAGUER, 2013c).

Reverter esta involução democrática e constitucional não será tarefa fácil. Certamente, a melhoria da situação econômica da zona Euro pode contribuir para que, de alguma forma, os pactos constitucionais se regenerem. No entanto, a Constituição não pode se ver submetida ao vai e vem dos ciclos econômicos, de tal forma que cada vez que ocorra uma situação de crise passe à posição de "stand by" até que a crise se supere. $\bigcirc$ que a crise econômica no ensinou, é que estes grandes pactos constitucionais dificilmente poderão ser mentidos, olhando-se para o futuro, exclusivamente no âmbito do Estado Nacional. Pelo contrário, cada vez se torna mais necessário promove-los no plano europeu e com perspectiva europeia, para que possam ser eficazes e não dependam das condições à quais os mercados globais possam submeter os Estados nacionais. Ampliar o círculo de decisão nacional requer que se assuma a necessidade de intensificar a integração política supranacional, já que na Europa, como em qualquer outra região do mundo, os Estados nacionais de pequeno ou médio porte não terão, por si só (salvo circunstâncias especiais) a dimensão necessária para afrontar a globalização.

No entanto, uma Europa construída em grande medida de costas para o constitucionalismo e que contribuiu para esvaziar sua legitimidade mediante a imposição de uma intepretação econômica da Constituição, incompatível com o patrimônio constitucional europeu, não poderá avançar no processo de integração política enquanto não se modifique o atual modelo. As duas 
grandes crises do constitucionalismo foram, ao mesmo tempo duas grandes crises da União Europeia e não por casualidade. Somente uma Europa que recupere a legitimidade do constitucionalismo como movimento civilizatório poderá aspirar construir uma integração política plena e salvar assim o projeto europeu frente a seus, cada vez mais numerosos, inimigos.

\section{A internalização do poder dos agentes globais através das redes sociais}

A preocupação com a influência negativa que as redes sociais podem estar exercendo nos processos democráticos e com a lesão que podem provocar nos direitos fundamentais é muito recente. Em seus primeiros anos de desenvolvimento (tampouco muito distante, certamente) as redes foram percebidas como uma oportunidade para incrementar a participação política, facilitar os processos democráticos e, inclusive, promover transições de regimes autoritários para a democracia. Esta visão positiva não desapareceu, pois o potencial das redes sociais continua sendo enorme no que tange às possibilidades de potencialização democrática. No entanto, nos últimos tempos, destacaramse, também os problemas que as redes sociais provocam em relação aos direitos fundamentais, assim como a incidência que podem estar manifestando na configuração do espaço público dos sistemas democráticos. Finalmente, ultimamente, pudemos comprovar igualmente a atividade que as plataformas que gerenciam as redes sociais e outros agentes podem desenvolver em relação à manipulação da propaganda eleitoral, a difusão de fake news e o impacto nos processos eleitorais.

Com efeito, desde não mais que alguns meses tomamos conhecimento de alguns fatos que previamente eram tidos como meras hipóteses de trabalho. É o caso da intervenção de Cambridge Analytica / Facebook no referendo do Brexit e nas eleições presidenciais norte-americanas (SCOTT, 2018). Certamente nos próximos meses sairão à luz mais dados, conforme avancem as investigações em curso. A interação entre redes sociais e democracia começa a ficar problemática. A reflexão em torno desta crescente tensão concentrou-se até o momento na incidência negativa das redes sociais sobre o espaço público na medida em que a criação de perfis acaba por gerar filtros que produzem bolhas (PARISER, 2011) nas quais os usuários ficam "isolados", provocando diversas disfunções. Entre estas, a fragmentação do espaço público, a radicalização crescente dos diversos setores de opinião que se movimentam dentro destas "bolhas", a proliferação das fake news, que se vê favorecida pela lógica da polarização (STEIN, 2018) e, em última instância, a dissolução do "público" unitário (PALANO, 2017) que se encontrava na base da "democracia do público" (MANIN, 1997) e que havia promovido, do ponto de vista do espaço comunicativo, a convergência dos partidos em direção ao centro político e à moderação.

Em geral, há um universo de questões sendo colocadas no terreno da comunicação política e no âmbito de sua incidência sobre a democracia. No entanto, os fatores constitucionais, que poderiam ser muito úteis para a caracterização dos problemas e para a proposta de alternativas, dificilmente entraram em jogo. Tudo mais, em trabalhos muito notáveis, em relação às fake News, 
para destacar a insuficiência da caracterização doutrinária da Primeira Emenda da Constituição dos Estados Unidos no sentido de abordar este problema (SCHAUER, 2010) ou para ressaltar a distinta percepção que se tem no Direito Europeu, do ponto de vista não tanto da liberdade de expressão, como do direito à informação (informação verídica) que possibilita uma intervenção maior do poder público (POLLICINO, 2017).

Uma grande parte da atividade potencialmente lesiva aos direitos da coletividade que tais plataformas desenvolvem era tecnicamente impensável há não muitos anos e, portanto, alheia a qualquer regulação estatal, supranacional ou internacional. $O$ problema é que, antes que se tenha podido estabelecer normas destinadas a disciplinar tais atividades, já se configuram outras, cujo alcance ainda não conhecemos e que também são potencialmente lesivas (pensemos, por exemplo, no possível uso massivo de dados pessoais através do "bitcoin trader". Sem que tenhamos terminado de superar a primeira grande crise do constitucionalismo deste século XXI, que surgiu como consequência da crise financeira de 2009 e da imposição de uma interpretação econômica da Constituição, que minou as bases da democracia pluralista, reduzindo direitos sociais, revertendo a descentralização política e debilitando ao extremo a normatividade da Constituição (CALLEJÓN, 2015a), nos encontramos agora com uma nova crise de um alcance potencialmente mais destrutivo, se é possível, porque afeta o próprio núcleo dos processos democráticos e constitucionais internalizando o poder dos grandes agentes globais através das redes sociais.

O impacto sobre o núcleo dos processos democráticos evidenciado com a intervenção de Cambridge Analytica no referendo do Brexit assim como aquela desta mesma companhia e do Facebook sobre as eleições presidenciais norte-americanas (que foram seguidas das intervenções de outros agentes globais em sucessivos processos eleitorais na Holanda e na França, por exemplo) suscita questionamentos muito sérios para o futuro do constitucionalismo e da democracia pluralista. As possibilidades de manipulação política massiva dos processos eleitorais, no âmbito digital, por meio da propaganda "subliminar" elaborada através de milhões de perfis gerados mediante algoritmos, permitindo condicionar de forma personalizada a orientação do voto dos usuários das redes sociais, não tem precedente algum na história. $O$ fato de que esta atividade tenha podido se desenvolver sem impedimento legal e com uma finalidade comercial resulta ainda mais perturbador.

Da perspectiva do Direito Constitucional esta não é a única inquietude provocada pelas redes sociais. Pensemos na fragmentação do espaço público, a polarização das atitudes políticas, a radicalização do discurso e da linguagem com a conseguinte lesão dos direitos fundamentais, a dificuldade, quando não a impossibilidade, de articular consensos num clima político cada vez mais estranho, ausência de legitimação permanente da política, a apelação às próprias redes como mecanismo de legitimidade e representatividade, potencializando movimentos populistas e antidemocráticos, entre outros muitos sinais de que a democracia pluralista e a Constituição normativa estão vivendo suas horas mais difíceis. 
$\mathrm{Na}$ base desta evolução estão as condições sociais de conflito radical que configuram o substrato da polarização, que acaba por se transferir às redes sociais, intensificando-se através delas, e com uma solução muito complicada atualmente, devido a dois fatores que convergem para dificultá-la. O primeiro deles, as soluções econômicas possíveis, se situam já fora do Estado, no contexto global, o que explica a insegurança com a qual estes tempos são percebidos por amplos setores sociais que já não enxergam o Estado como um tutor eficaz de seus direitos (BAUMAN, 2007). No caso da Europa, ainda não existe uma estrutura supranacional suficientemente integrada e eficaz a ponto de agir de forma unitária no plano global, o que dificulta igualmente a solução neste nível. Isto explica que muitos textos constitucionais tenham aumentado sua divergência com a realidade, especialmente em matéria de direitos e de governo econômico, a partir da crise financeira. A mudança de paradigma afeta também a Constituição, que perdeu sua posição de centralidade no espaço público e encontra-se cada vez mais isolada, na medida em que não é compreendida como um instrumento eficaz de controle do poder financeiro e de concretização dos direitos da coletividade.

$O$ segundo destes fatores tem a ver especificamente com os processos comunicativos derivados das redes sociais. Apesar de que estas como instrumento tenham sido e continuem sendo uma esperança para o aprofundamento democrático, produz-se um paradoxo devido à forma como se configuraram até o momento. Uma autêntica contradição entre o que se esperava delas e o que fazem e que tem sua explicação no fato de que as redes, embora abram passo a amplos processos comunicativos e eventualmente participativos, não têm uma estrutura democrática e participativa em sua configuração. Não apenas isso, trata-se, ademais, de plataformas que funcionam em regime de monopólio ou oligopólio (FROSINI, 2017) e que têm um interesse centrado na obtenção de recursos por meio da publicidade, razão pela qual é difícil esperar que possam contribuir para serenar o debate público e facilitar a participação democrática na solução dos problemas sociais. Estas plataformas, com a lógica do benefício econômico, precisam chamar a atenção do público para aumentar sua receita publicitária (DEB; DONOHUE; GLAISYER, 2017). Com esta perspectiva, a instabilidade política e o conflito social favorecem seus objetivos, retroalimentando, assim, os efeitos perniciosos do "bubble filter" e a polarização por este produzida.

Podemos arriscar afirmar que o resultado do referendo sobre o Brexit ou a eleição de Donald Trump como Presidente dos Estados Unidos, melhoraram as perspectivas de negócio das grandes plataformas que gerenciam as redes sociais, não por Donald Trump ser um fanático por uma delas, e sim pela instabilidade que ambos os processos eleitorais geraram em seus respectivos países. Estas plataformas ganham sempre: com o Brexit e com as intermináveis discussões que provoca na rede e que teriam sido muito menos intensas e numerosas se o resultado do referendo tivesse sido distinto. Ganham também com a eleição de Donald Trump e com os contínuos debates que o novo Presidente dos Estados Unidos provoca em seu país e no mundo, alterando as condições de desenvolvimento da política das Administrações anteriores. 
Por outro lado, os meios técnicos à disposição das redes sociais a fim de manipular a opinião pública são extraordinários e não têm precedente na história da humanidade, como ficou claro pela intervenção de Cambridge Analytica e Facebook nas eleições presidenciais norte-americanas. Sempre houve fake News e propaganda política com instrumentos muito eficazes como o foram no século $\mathrm{XX}$ o rádio e a televisão. $\mathrm{O}$ que diferencia os meios atuais dos anteriores é que, através dos perfis elaborados mediante algoritmos e do envio personalizado de propaganda, é possível condicionar a opinião e o voto de maneira extremamente eficaz. Tanto que não depende do nível de educação dos destinatários, e não somente porque esta propaganda funcione dentro da "bolha" previamente identificada das preferências políticas, mas sim porque atua num nível mais perigoso, no da psicologia dos usuários das redes sociais, mediante técnicas que permitem utilizar medos ocultos ou inclinações das quais sequer são conscientes, porém, que são do conhecimento das plataformas mediante a análise de sua atividade na internet.

Conforme podemos ver, o constitucionalismo de nosso tempo não está passando pelo seu melhor momento. Frente à época dourada iniciada com as constituições normativas, nos últimos anos estamos experimentando um processo duplo de involução externa interna que se reflete, no âmbito externo nas limitações da capacidade de ação não somente do Estado nacional, mas também das instituições supranacionais (que fazem parte igualmente da realidade constitucional) gerada pela globalização. No âmbito interno, tem sua manifestação mais evidente na configuração regressiva do espaço público provocada pelas redes sociais, em relação aos princípios que inspiram o debate público e a atividade política na Constituição normativa. Ambos os processos de involução, externo e interno, alimentam-se reciprocamente, de maneira que, quanto menor seja a capacidade do Estado e da União Europeia para resolver os problemas sociais, maior será a degradação do debate público interno gerado através das redes sociais. Porém, ao mesmo tempo, quanto maior é a erosão do espaço público interno, maiores as dificuldades quem tem o Estado de atuar de forma eficaz no exercício de suas funções constitucionais e a União Europeia para oferecer à coletividade um projeto sério de integração supranacional que somente pode se basear em parâmetros constitucionais.

\section{Um constitucionalismo marginal e sem legitimação no contexto global}

No nível democrático do governo ordinário de uma sociedade, os fenômenos de polarização, conflito, sectarismo inclusive, são até certo ponto controláveis (até certo ponto, certamente), porque fazem parte dos processos de debate e decisão próprios da democracia pluralista. No nível constitucional, no entanto, significam uma prova de fogo para a própria existência do constitucionalismo. Se a fragmentação do espaço público, a instabilidade e o enfrentamento entre setores sociais não permite chegar a consensos constitucionais (seja para a aprovação de novas constituições, seja para a reforma das existentes) estaríamos ante uma crescente inoperância e isolamento do Direito Constitucional em relação à sociedade, o que determinaria, em médio prazo, o 
fim da Constituição tal e como a conhecemos até o momento. Em relação ao Direito Constitucional, as redes sociais adiantam também uma mudança de paradigma, na qual não basta simplesmente pensar na regulação das redes para adaptá-las às exigências próprias do constitucionalismo, mas que, como em toda interação dialética, se faz necessário questionar o que temos que mudar no Direito Constitucional de nosso tempo para adaptá-lo às redes sociais e aos novos processos comunicativos e sociais engendrados.

A transformação dos padrões culturais e a mudança de paradigma sugerida afetarão a forma de compreender o direito constitucional até o momento, o que implica também uma nova concepção do espaço público e dos direitos e a democracia, determinada pelo desenvolvimento tecnológico e comunicativo. Porém, ao mesmo tempo, faz-se necessário corrigir os elementos disfuncionais na configuração atual das redes sociais e no seu uso por grandes plataformas e agentes globais, que é suscetível de provocar uma involução democrática. Estamos ante uma nova fronteira, cujos contornos precisos não foram ainda desvelados, e que irá se descortinando nos próximos anos.

A coexistência de processos constitucionais e redes sociais não é fácil, e podemos destacar algumas contradições importantes que são perceptíveis na relação com o Direito Constitucional das constituições normativas:

1. As constituições normativas baseiam-se no consenso fundamental da sociedade, articulado através de processos constituintes nos quais encontram-se representados todos os setores sociais, que entram em acordo em relação a um projeto de convivência comum e o atualizam igualmente por consenso mediante reformas constitucionais. Estes consensos são cada vez mais difíceis de lograr devido à polarização crescente do espaço público, potencializada em grande medida pelas redes sociais.

2. As constituições normativas têm uma vocação de ordenação global da sociedade, regulando a totalidade da ação do Estado e controlando o poder público para garantir direitos. Esta pretensão continua se mantendo, embora o poder dos Estados membros da EU já não tenha essa vocação de totalidade porque é compartilhado com as instâncias europeias (CALLEJÓN, 2016). No entanto, as redes sociais parecem produzir uma fragmentação acrescida do espaço púbico, com diversidade de interesses setoriais, que dificultam uma ordenação compreensiva do conjunto da sociedade mediante instrumentos constitucionais.

3. As constituições normativas definem uma estrutura de convivência estável, uma programação no tempo para as gerações sucessivas. $\bigcirc$ fator tempo é de grande relevância no Direito constitucional, como também nas redes sociais, porém de forma contraditória. Nestas, o caráter imediato da resposta, própria do processo comunicativo configurado através delas, está dando ensejo a processos políticos nos quais a planificação em médio ou longo prazo não parece ter qualquer utilidade. Requerem-se cada vez mais respostas diretas e imediatas que sirvam para resolver problemas que são complexos e estão cheios de matizes e exigirão uma ordenação temporal distinta. 
4. A maior parte das constituições dos Estados membros da EU tem uma estrutura normativa, o que implica a utilização de técnicas e instrumentos de caráter jurídico para a realização de suas funções através de processos formalizados que incorporam garantias jurídicas complexas. Esta complexidade pode ser tão difícil de compreender como operações matemáticas ou processos químicos sobre os quais o debate científico está reservado a especialistas na matéria. No entanto, no contexto de uma sociedade democrática os debates sobre a Constituição não podem ser limitados. Ao contrário, a sociedade aberta dos intérpretes constitucionais (HABERLE, 1975) deve ser preservada. Porém, o debate nas redes sociais parece estar orientando-se cada vez mais no sentido contrário aos valores constitucionais de respeito à dignidade e aos direitos (potencializando o racismo, a xenofobia e a misoginia, por exemplo).

5. O radicalismo e a intolerância gerados nas redes estão se transferindo em grande medida para o debate público fora das redes, o que ainda resulta mais problemático do ponto de vista constitucional. As redes parecem estar desenvolvendo uma função de reprodução cultural negativa na medida em que "educam" amplos setores da população no enfrentamento e na escalada de tensões dentro e fora das redes. No plano político, essas atitudes sociais negativas incrementam a agressividade no espaço público, aumentando a dificuldade para alcançar acordos entre os agentes políticos.

6. A crescente dependência dos meios de comunicação tradicionais em relação às redes sociais é também um fator a ser considerado (PITRUZZELA, 2017). Para poder competir no mercado publicitário, os meios de comunicação parecem estar se adaptando gradativamente ao discurso das redes, tanto no que se refere aos conteúdos (muitos deles superficiais, que banalizam os debates públicos) quanto à forma de apresentá-los e manuseá-los, em muitas ocasiões conectados não só com as temáticas como também com a forma como estão sendo abordados nas redes sociais.

7. Os partidos políticos parecem manifestar igualmente uma dependência crescente das redes sociais em sua atividade. Suas agendas encontram-se condicionadas pelos debates nelas gerados e suas orientações dependem em grande parte das polêmicas lançadas nas redes. Isto não seria em si mesmo disfuncional, porque expressaria um incremento da participação política, se não fosse pelo fato de que há indícios que nos fazem pensar que tais debates se introduzem nas redes em muitas ocasiões por meio de estruturas organizadas e de agentes que desejam orientá-los e priorizálos em função de interesses ocultos. Ademais, neste ponto está se produzindo um risco de involução democrática com a intervenção de tais agentes nos processos eleitorais em favor de determinados partidos e opções políticas.

Como podemos ver, a situação do constitucionalismo é cada vez mais problemática neste contexto, determinado pelas duas grandes crises experimentadas no século XXI. A Constituição deixa de cumprir suas funções e se desloca a um lugar marginal em relação aos conflitos sociais e aos processos políticos, definidos agora por outros traços, externos e internos, diferentes daqueles que haviam impulsionado as constituições normativas a uma posição central na sociedade. Ao mesmo tempo, sua legitimidade se degrada justamente pelo fato de que, ante a Constituições se 
opõe a economia como fator de legitimação e o desenvolvimento tecnológico como limite. Em ambos os casos são condicionadas as políticas públicas, os direitos fundamentais e os parâmetros de constitucionalidade. As limitações aos direitos pretendem se justificar em razão da inevitabilidade das premissas econômicas de austeridade, incondicionalmente aceitadas ou pela impossibilidade de articular mecanismos técnicos para protege-los frente as redes sociais ou as grandes plataformas de Internet. Uma legitimidade mais forte pretende suplantar o constitucionalismo. Uma legitimidade que está ao serviço dos grandes interesses econômicos globais.

\section{Considerações finais. Restaurar a legitimidade do constitucionalismo}

As duas grandes crises do constitucionalismo no século XXI se expressam na dificuldade do Direito Constitucional em cumprir as funções que historicamente foram atribuídas ao constitucionalismo e, em particular, canalização dos conflitos sociais mediante a articulação do pluralismo e a construção de acordos políticos e consensos constitucionais. As dificuldades são objetivas e se manifestam na incapacidade do Estado em desenvolver políticas próprias que permitam garantir os direitos da coletividade num mundo globalizado, por um lado e, por outro lado, na gradativa configuração desagregadora de um espaço público no qual as redes sociais têm um especial protagonismo na conformação da opinião pública, substituindo os meios de comunicação tradicionais.

Ambos os fatores convergem, interagem e se alimentam reciprocamente, de forma que a democracia pluralista se vê ameaçada pelas condições externas da globalização, que reduzem o círculo das decisões políticas possíveis no espaço público nacional e pelas condições estruturais internas da comunicação através das redes sociais, dificultando um debate racional que facilite a adoção de acordos políticos e de consensos constitucionais. Não é, certamente, o fim da Constituição, porém, o século XXI esá se configurando como um século gradativamente "aconstitucional" para defini-lo de alguma forma, e a Constituição normativa que conhecemos desde a segunda metade do século XX, demonstra-se cada vez mais ineficaz e inoperante devido a tais fatores externos e internos.

A solução para restaurar a legitimidade do constitucionalismo já não se encontra nas mãos do Estado e da Constituição nacional, mas depende do contexto supranacional, isto é, da capacidade que tenha a coletividade para constitucionalizar a União Europeia e definir um âmbito de decisão europeu que possa recuperar em âmbito supranacional as funções da Constituição. Somente a União Europeia tem a magnitude necessária para afrontar a globalização, ampliando o círculo de decisões políticas (incluindo o dos Estados membros e de suas constituições internas). É também a União Europeia que pode adotar medidas no âmbito das redes sociais que mitiguem os efeitos dos discursos desagregadores veiculados através delas e que controlam o extraordinário poder que tem agora os provedores de Internet. A integração supranacional europeia, uma vez que se configure de maneira plenamente constitucional e democrática através de um Estado federal europeu, será também o 
instrumento de recuperação das funções da Constituição e de plena ativação da democracia pluralista, não só em nível europeu, mas também em nível interno nos Estados membros.

Questões essenciais para a construção europeia definir-se-ão nos próximos anos se levamos em consideração o fato de que as redes estão potencializando os discursos nacionalista e xenofóbico, e orientando o debate no espaço público europeu no sentido do primado de interesses nacionais, o que impede um entendimento aberto da identidade nacional (CALLEJÓN, 2017a) e dificulta a construção de uma identidade europeia. A integração europeia é absolutamente necessária para fazer frente à globalização e para controlar o poder de agentes que já não encontram no Estado nacional um limite. $O$ fato de que as duas grandes crises do constitucionalismo tenham sido também duas grandes crises europeias evidencia que estamos num momento crucial da vida do processo de integração europeia e da evolução do constitucionalismo, no qual ambos os projetos civilizatórios devem convergir para sobreviver no contexto global.

\section{Referências}

BARRILAO, Juan Francisco Sánchez. Derecho europeo y globalización: mitos y retos en la construcción del Derecho Constitucional Europeo. Revista de Derecho Constitucional Europeo, n. 12, jul./ dic. 2009.

BARRILAO, Juan Francisco Sánchez. El futuro jurídico de Internet: una aproximación constitucional a la neutralidad de la red. Revista de Derecho Constitucional Europeo, n. 26, 2016. Disponível em: http://www.ugr.es/ redce/REDCE26/articulos/06_BARRILAO.htm. Acesso em: 30 out. 2018.

BARRILAO, Juan Francisco Sánchez. El Internet en la era Trump: aproximación constitucional a una nueva realidade. No prelo.

BAUMAN, Zygmunt. Liquid Times: Living in an Age of Uncertainty. Cambridge: Polity Press, 2007.

CALLEJÓN, Francisco Balaguer. A relação dialética entre identidade constitucional nacional e europeia, no quadro do Direito Constitucional Europeu. UNIO - EU Law Journal, v. 3, n. 1, p. 10-24, 2017a. Disponível em: http://www.unio.cedu.direito.uminho.pt/Uploads/UNIO\%203/Corrigidos/ francisco_balaguer_callejon.pdf. Acesso em: 18 nov. 2018.

CALLEJÓN, Francisco Balaguer. Alcune lezioni della Brexit per il Diritto costituzionale europeo. Referendum e Social Network versus democracia pluralista. No prelo. Liber Amicorum Silvio Gambino, 2018a.

CALLEJÓN, Francisco Balaguer. Constitución y Estado en el contexto de la integración supranacional y de la globalización. In: CARBONELL, Miguel et al. (coord.). Estado constitucional, Derechos humanos, Justicia y vida universitaria. Estudios en Homenaje a Jorge Carpizo. México: UNAM, 2015b. t. IV, v. 1. p. 197-211.

CALLEJÓN, Francisco Balaguer. Constitutional Courts under Pressure: New Challenges to Constitutional Adjudication. The Case of Spain. In: SZENTE, Zoltán; GÁRDOS-OROSZ, Fruzsina (ed.). New Challenges to Constitutional Adjudication in Europe. A Comparative Perspective. Londres: Routledge Editora, 2018b. p. 164-184. 
CALLEJÓN, Francisco Balaguer. Crisi economica e crisi costituzionale in Europa. KorEuropa, Enna, n. 1, 2012a. Disponível em: https://www.unikore.it/media/k2/attachments/Francisco_Balaguer_ Callejon_numerato.pdf. Acesso em: 25 out. 2018.

CALLEJÓN, Francisco Balaguer. Crisis económica y crisis constitucional en Europa, Rev. Española de Derecho Constitucional, n. 98, p. 91-107, mayo/agosto 2013a. Disponível em: https://recyt.fecyt. es/index.php/REDCons/article/view/39779/22466. Acesso em: 25 out. 2018.

CALLEJÓN, Francisco Balaguer. Diritto e giustizia nell'ordinamento costituzionale europeo. In: CANTARO, Antonio. Giustizia e diritto nella scienza giuridica contemporânea. Torino: G. Giappichelli Editora, 2011. p. 31-49.

CALLEJÓN, Francisco Balaguer. El final de una época dorada: Una reflexión sobre la crisis económica y el declive del Derecho constitucional nacional. In: CORREIA, Fernando Alves (coord.). Estudos em Homenagem ao Professor Doutor José Joaquim Gomes Canotilho - Vol. II, Constituição e Estado: entre Teoria e Dogmática. Coimbra: Coimbra Editora, 2012b. p. 99-122.

CALLEJÓN, Francisco Balaguer. European Identity, Citizenship and the Model of Integration. In: SILVEIRA, Alessandra; CANOTILHO, Mariana; FROUFE, Pedro Madeira (ed.). Citizenship and Solidarity in the European Union - from the Charter of Fundamental Rights to the crisis, the state of the art. Bruxelas: PIE - Peter Lang, 2013b.

CALLEJÓN, Francisco Balaguer. European Integration and Limitation of the Power of Constitutional Reform. In: ARNOLD, Rainer (ed.). Limitations of National Sovereignty through European Integration. [S. l.]: Springer, 2016. p. 15-25.

CALLEJÓN, Francisco Balaguer. La prospettiva spagnola sul pilastro sociale europeo. Milão. No prelo.

CALLEJÓN, Francisco Balaguer. Potere costituente e limiti alla revisione costituzionale visti dalla Spagna. In: LANCHESTER, Fulco (org.). Costantino Mortati. Potere costituente e limiti alla revisione costituzionale. Padova: Cedam, 2017b. p. 85-112.

CALLEJÓN, Francisco Balaguer. Primato del diritto europeo e identità costituzionale nell'esperienza spagnola. In: BERNARDI, Alessandro. I Controlimiti - Primato delle norme europee e difesa dei principi costituzionali. Nápoles: Jovene Editore, 2017c. p. 113-133.

CALLEJÓN, Francisco Balaguer. Profili metodologici del Diritto Costituzionale europeo. La cittadinanza europea, n. 1, p. 39-62, 2015 b.

CALLEJÓN, Francisco Balaguer. Una interpretación constitucional de la crisis económica. Rev. de Derecho Constitucional Europeo, n. 19, 2013c. Disponível em: https://www.ugr.es/ redce/REDCE19/ articulos/15_F_BALAGUER.htm. Acesso em: 29 out. 2018.

D'ATENA, Antonio. Tensioni e sfide della democrazia. Rivista AIC, n. 1, 2018. Disponível em: http://www.rivistaaic.it/tensioni-e-sfide-della-democrazia.html. Acesso em: 28 out. 2018.

DEB, Anamitra; DONOHUE, Stacy; GLAISYER, Tom. Is Social Media a Threat to Democracy? 2017. Disponível em: https://www.omidyargroup.com/wp-content/uploads/2017/10/Social-Media-and-Democracy-October-5-2017.pdf. Acesso em: 29 out. 2018. 
DE CABO, Carlos. Constitucionalismo del Estado social y Unión Europea en el contexto globalizador. Revista de Derecho Constitucional Europeo, n. 11, jan./jun. 2009.

FERGUSON, Niall. Social networks are creating a global crisis of democracy. The Globe and the Mail, Toronto, 2018. Disponível em: https://www.theglobeandmail.com/opinion/niall-ferguson-social-networks-and-the-global-crisis-of-democracy/article37665172/. Acesso em: 20 out. 2018.

FROSINI, Tommaso Edoardo. Internet e democrazia. Il diritto dell'informazione e dell'informatica, ano XXXII, fasc. 4-5, p. 657-671, 2017.

GAMBINO, Silvio. Crisi economica e costituzionalismo contemporâneo: Quale futuro europeo per i diritti fondamentali e per lo Stato sociale. ASTRID Rassegna, n. 5, 2015. Disponível em: http:// www.europeanrights.eu/public/commenti/Gambino_Crisi-economica-e-Stato-sociale-1.pdf. Acesso em: 29 out. 2018.

GRASSO, Giorgio. Le parole della Costituzione e la crisi economico-finanziaria. Osservatorio AIC, 2016. Disponível em: https://www.osservatorioaic.it/images/rivista/pdf/Giorgio\%20Grasso\%20 Osservatorio\%20Costituzionale\%20febbraio\%202016.pdf 1. Acesso em: 20 out. 2018.

GUILLÉN LÓPEZ, Enrique. La crisis económica y la dirección política: reflexiones sobre los conceptos de necesidad y de elección en la teoría constitucional. Revista de Derecho Constitucional Europeo, n. 20, jul./dic. 2013.

HÄBERLE, Peter. Die offene Gesellschaft der Verfassungsinterpreten: Ein Beitrag zur pluralistischen und prozessualen Verfassungsinterpretation. JuristenZeitung, p. 297-305, 1975.

MANIN, Bernard. The principles of representative government. Cambridge: Cambridge University Press, 1997.

NOCITO, Walter. Diritti costituzionali e crisi finanziaria: la rigidità costituzionale alla prova. Revista de Estudios Jurídicos, n. 15, 2015.

PALANO, Damiano. La bolla mortale della nuova democrazia. Il Foglio, 1 maio 2017. Disponível em: https://www.ilfoglio.it/politica/2017/05/01/news/la-bolla-mortale-della-nuova-democrazia-132173/. Acesso em: 19 out. 2018.

PARISER, Eli. The Filter Bubble: What the Internet Is Hiding from You. [S. l.]: Penguin Books, 2011.

PITRUZZELLA, Giuseppe. La libertà di informazione nell'era di Internet. In: PITRUZZELA, Giovanni; POLLICINO, Oreste; QUINTARELLI, Stefano. Parole e potere: Libertà d'espressione, hate speech e fake news. Egea: Italian Edition, 2017.

POLLICINO, Oreste. La prospettiva costituzionale sulla libertà di espressione nell'era di Internet. In: PITRUZZELA, Giovanni; POLLICINO, Oreste; QUINTARELLI, Stefano. Parole e potere: Libertà d'espressione, hate speech e fake news. Egea: Italian Edition, 2017.

RAIMONDO, Natália Ansemino REVIGLIO, María Cecilia; DAVIANI, Ricardo. Esfera pública y redes sociales en Internet: ¿Qué es lo nuevo en Facebook? Revista Mediterránea de Comunicación, v. 7, n. 1, p. 211-229, 2016.

CANOTILHO, Mariana Rodrigues. La crisis económica (y social) de los países en crisis. Revista de Derecho Constitucional Europeo, n. 23, enero/jun. 2015. 
RUGGERI, Antonio. Il futuro dei diritti fondamentali e dell'Europa. Consulta On Line, fasc. 3, 2016. Disponível em: http://www.giurcost.org/studi/ruggeri59.pdf. Acesso em: 09 nov. 2018.

SÁNCHEZ, Miguel Arjona. La libertad de capitales en Europa: Una mirada constitucional sobre la red jurídica sobre la que se forjan y mueven los capitales en la era de la globalización. 2017. TeseUniversidade de Granada, Granada, 2017.

SCHAUER, Frederick, 2010. Facts and the First Amendment. UCLA Law Review, v. 57, p. 897-919, 2010. Disponível em: https://www.uclalawreview.org/pdf/57-4-1.pdf.

SCHILLACI, Angelo. Crisis económica, participación y reformas de las administraciones públicas. Revista de Derecho Constitucional Europeo, ano 11, n. 22, p. 15-27, jul./dic. 2014.

SCOTT, Mark. Cambridge Analytica helped 'cheat' Brexit vote and US election. Politico, 29 mar. 2018. Disponível em: https://www.politico.eu/article/cambridge-analytica-chris-wylie-brexit-trump-britain-data-protection- privacy-facebook. Acesso em: 09 nov. 2018.

SUNSTEIN, Cass Robery. \#Republic: Divided Democracy in the Age of Social Media. Princeton: Princeton University Press, 2018.

VECCHIO, Fausto. Crisis económica y evolución de la Administración Pública en Europa. Revista de Derecho Constitucional Europeo, n. 23, enero/jun. 2015. 
